\title{
Fatigue management methodology in aircraft maintenance as a way of reducing errors related to the human factor
}

\author{
Alexandra Rybalkina $^{1 *}$, Ruslan Enikeev ${ }^{2}$ \\ ${ }^{1}$ Moscow State Technical University of Civil Aviation, 125993, Moscow, 20 Kronshtadtsky blvd, \\ Russia \\ ${ }^{2}$ S 7 ENGINEERING LLC, 142015, Domodedovo, bld. 6/1 Domodedovo Airport estate, Russia
}

\begin{abstract}
Maintenance staff fatigue is one of the key factors contributing to the occurrence of errors in the maintenance. The problem of maintenance staff fatigue is a serious challenge for aircraft maintenance organizations, and its solution is directly related to the impact on flight safety. The authors consider the issues of the fatigue effect on the maintenance staff performance and related consequences. The article provides the results of the maintenance staff fatigue research, obtained through a survey of one of the organizations' employees. According to the survey, errors are the most likely outcome of work in a state of fatigue in aircraft maintenance. The obtained results made it necessary to develop a methodology for managing maintenance staff fatigue in aircraft maintenance. The methodology is based on a questionnaire, where the respondents are asked to answer questions regarding their state of fatigue, and fatigue assessment criteria. The assessment results make it possible to develop the necessary corrective and preventive measures, including the privilege limitation and suspension to perform maintenance tasks.
\end{abstract}

\section{Introduction}

Maintenance staff fatigue have a dangerous effect both on the quality of the work performed and on the flight safety [1]. When a person is in a state of fatigue, his reaction slows down, the ability to sound judgment decreases, difficulties in focusing attention appear $[2,3]$, in this state a person is more prone to lapses, a person becomes unsociable and uncommunicative.

One of the most obvious hazard of fatigue $[4,5,6]$ is the loss of the body's ability to stay awake while at work. In a state of fatigue, a person, while performing maintenance, can fall asleep for a moment (from 2 to 30 seconds), starting to enter the first stage of sleep, while their eyes still open. In such situations, a person is usually unaware of his state of fatigue and may continue to perform simple repetitive maintenance tasks while sleeping. Such influence can lead to catastrophic outcome in aircraft maintenance, for example,

\footnotetext{
* Corresponding author: rybalkina@list.ru
} 
during rigging, when lifting the aircraft, during installation, when operating equipment or driving a vehicle.

\section{Maintenance fatigue research}

The authors conducted a study, during which 114 maintenance staff of one of the organizations were interviewed. The survey showed that $80 \%$ of maintenance staff noticed the occurrence of errors when working in state of fatigue, $34 \%$ noticed that working in a state of fatigue could be a threat to flight safety (Table 1).

Table 1. Consequences of work in a state of fatigue

\begin{tabular}{|c|c|}
\hline Consequences of work in a state of fatigue & $\begin{array}{c}\text { Percent of employees who noticed the } \\
\text { consequences of work in a state of fatigue }\end{array}$ \\
\hline Errors & $80 \%$ \\
\hline Flight safety threat & $34 \%$ \\
\hline Financial losses & $11 \%$ \\
\hline Threats to the health and life of employees & $27 \%$ \\
\hline
\end{tabular}

The survey showed that, errors caused by fatigue are associated with a deterioration in attention, memory, decreased activity, deterioration in mood and an increase in reaction time (Fig. 1).

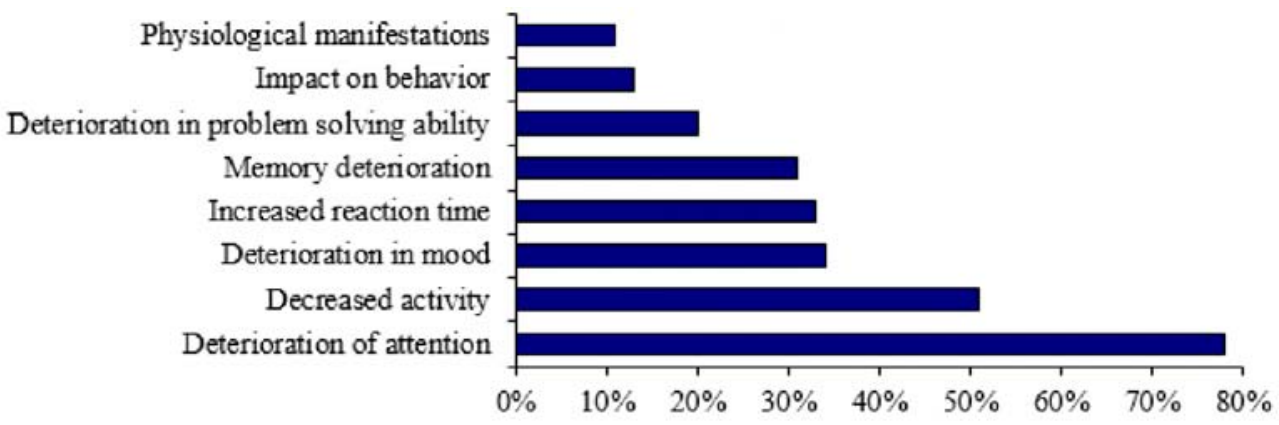

Fig. 1. Assessment of the fatigue impact on the efficiency according to the survey results

There are two common types of fatigue-related errors in aircraft maintenance forgetfulness and inability to detect defects or problems. Maintenance staff in a state of fatigue are more likely to forget to perform routine actions, for example, replacing oil caps of the aircraft engine, and are more susceptible to distraction.

In the lack of attention and poor concentration as a result of fatigue, it is more difficult for maintenance staff to detect defects during inspections [7], and may be less likely to notice activity-related problems. The effect of fatigue reduces performance of maintenance staff which negatively affects not only flight safety, but also leads to financial losses, for example, in case of aircraft departure delays due to technical reasons, an air turnback of an aircraft caused by a gear lock pin left in place, or the need for re-work.

Rest, corresponding to the effort that caused fatigue, leads to the disappearance of fatigue. If daily efforts turn out to be more than opportunities for rest, a person gradually reaches a state of chronic fatigue $[8,9]$, which is characterized by a lack of interest in work, a feeling of exhaustion, mental excitability, lack of appetite, a tendency to headaches and insomnia.

One of the chronic fatigue causes [10] may be exceeding the norm of working hours due to overtime work. 
The survey showed that work in the amount of more than 60 hours a week, according to $40 \%$ of the respondents, leads to increased drowsiness and fatigue, $30 \%$ noticed severe fatigue and difficulty in focusing attention (Table 2).

Table 2. Assessment of maintenance staff fatigue, depending on working hours subject to overtime work according to the survey results

\begin{tabular}{|c|c|c|c|c|}
\hline $\begin{array}{c}\text { Working hours } \\
\text { per week, } h\end{array}$ & $\begin{array}{c}\text { Activity, lack of } \\
\text { drowsiness }\end{array}$ & $\begin{array}{c}\text { Tolerable } \\
\text { alertness }\end{array}$ & Fatigue & $\begin{array}{c}\text { Severe fatigue, difficulty } \\
\text { in focusing attention }\end{array}$ \\
\hline Up to 40 & 0 & 71.4 & 14.3 & 14.3 \\
\hline $40-45$ & 16 & 52 & 32 & 0 \\
\hline $45-50$ & 9.7 & 48.4 & 29 & 12.9 \\
\hline $50-60$ & 10 & 50 & 40 & 0 \\
\hline More than 60 & 10 & 20 & 40 & 30 \\
\hline
\end{tabular}

\subsection{Sleep debt effect}

The amount of sleep which a person receives is of great importance for the recovery of body's functions while the person is awake. An adult needs to spend from 7 to 8 hours of sleeping every day. When less time is spent on sleep than the body needs to recuperate, a sleep debt occurs. Poor sleep quality (daytime sleep tends to be briefer and of poorer quality than sleep obtained at night), alcohol and drug use also lead to similar consequences. Currently, many people are suffering from sleep deprivation without being aware of it, as well as shift workers. Sleep debt has severe health effects and can affect ability to perform tasks in aircraft maintenance. The survey showed that $45 \%$ the respondents who were awake for 20 hours or more noticed the drowsiness and fatigue, $55 \%$ - severe fatigue and difficulty in focusing attention.

Regular restriction of night sleep (for 1-2 hours) leads to a progressive decrease in activity and performance every day [11]. The survey showed that $8 \%$ of the respondents sleep less than 3 hours a day, $11 \%$ - from 3 to 6 hours, $43 \%$ - from 6 to 7.5 hours, $32 \%$ from 7.5 to 9 hours, $6 \%$ - more than 9 hours. That is, $62 \%$ of those interviewed sleep less than 7.5 hours a day.

On the Epworth Sleepiness Scale, the mean is 10.1 with a total sleep duration of 3 days less than 18 hours, which is an indicator of excessive drowsiness. Such excessive drowsiness and fatigue are experienced by $36 \%$ of respondents with a total sleep duration for 3 days less than 18 hours (Table 3), while only 14\% noticed severe fatigue and difficulty in focusing attention. However, with a total sleep duration for 3 days from 19 to 22 hours, $35 \%$ of the respondents noticed excessive drowsiness and fatigue, and $13 \%$ severe fatigue and difficulty in focusing attention.

\subsection{Circadian rhythms effect}

The period from about 2 am to 5 am is normally intended for a person's sleep, therefore, the activity of their body at this time, including cogitative abilities, is at a minimum level. Shift work, especially at night, is most susceptible to fatigue effect and contributes to its accumulation [12]. 
Table 3. Assessment of maintenance staff fatigue, depending on the total duration of sleep (hours) for 3 days according to the survey results

\begin{tabular}{|c|c|c|c|c|}
\hline $\begin{array}{c}\text { Total sleep duration } \\
\text { for } 3 \text { days, } h\end{array}$ & $\begin{array}{c}\text { Activity, lack } \\
\text { of drowsiness }\end{array}$ & $\begin{array}{c}\text { Tolerable } \\
\text { alertness }\end{array}$ & Fatigue & $\begin{array}{c}\text { Severe fatigue, difficulty } \\
\text { in focusing attention }\end{array}$ \\
\hline $0-18$ & 4 & 46 & 36 & 14 \\
\hline $19-22$ & 22 & 30 & 35 & 13 \\
\hline $22.5-25.5$ & 9 & 55 & 27 & 9 \\
\hline More than 26 & 0 & 60 & 40 & 0 \\
\hline
\end{tabular}

The study results [6] have shown that errors can occur at any time of the day or night, however, a major part of them occur during the period around $3 \mathrm{am}$. The afternoon around $3 \mathrm{pm}$ is also prone to errors. In addition to the increased likelihood of making fatiguerelated error in aircraft maintenance, shift work also provokes errors associated with communication during shift hand over. Lack of communication due to fatigue can lead to loss, distortion, ambiguity of information during shift hand over.

\subsection{Monotonous task effect}

Monotonous maintenance tasks (for example, performing inspections) that require particular attention during the performance are most susceptible to fatigue impact.

The functional state of monotony can be characterized as a decrease in the level of vital activity as a result of exposure to monotonous stimuli [1]. The most significant factor in terms of detection efficiency is considered to be the distribution of breaks in observation [13]. At the same time, short and frequent breaks are preferable to long and rare ones, although in each case a check of this provision is required. Breaks increase the average detection rate, reduce the degradation of the observation quality, or decrease the variance of the missed signals.

The survey showed that $16 \%$ of respondents work without breaks, $33 \%$ - take breaks every hour, $16 \%$ - every 1.5 hours, $15 \%$ - every 2 hours, and $20 \%$ - every 3 hours or more. In this case, the duration of the break is most often from 5 to 15 minutes, in some cases the breaks duration is from 30 minutes to 1.5 hours.

\subsection{Other factors affecting maintenance staff fatigue}

Maintenance staff fatigue can also be influenced by other factors [14, 15] associated with the characteristics of the work performed or working conditions. The survey showed various factors causing increased maintenance staff fatigue depending on the work schedule (Table 4). For a full time employment, problems with working conditions (lighting, temperature, noise, ergonomics of the workplace, etc.), problems with sleep, boring, monotonous tasks, lack of time for the rest, a large amount of work and tight deadlines are noticed; for a two-shift day work - a large amount of work, problems with sleep, problems with working conditions, tight deadlines, boring, monotonous tasks; for a shift work (including night work)- a large amount of work, problems with sleep, problems with working conditions, tight deadlines, work schedule; for a flexible schedule (day - three) - a large amount of work, problems with sleep, problems with working conditions. 
Table 4. Factors increasing maintenance staff fatigue depending on the work schedule ( $\%$ of employees who noticed the influence of factors)

\begin{tabular}{|c|c|c|c|c|}
\hline $\begin{array}{c}\text { Factors increasing maintenance staff } \\
\text { fatigue }\end{array}$ & $\begin{array}{c}\text { Full time } \\
\text { employment }\end{array}$ & $\begin{array}{c}\text { Two-shift } \\
\text { day work }\end{array}$ & $\begin{array}{c}\text { Shift work (including } \\
\text { night work) }\end{array}$ & $\begin{array}{c}\text { Flexible } \\
\text { schedule }\end{array}$ \\
\hline $\begin{array}{c}\text { Working conditions (noise, lighting, } \\
\text { temperature, ergonomics of the } \\
\text { workplace, etc.) }\end{array}$ & $44 \%$ & $28 \%$ & $35 \%$ & $25 \%$ \\
\hline $\begin{array}{c}\text { Sleep problems (sleep debt, insomnia, } \\
\text { poor sleep quality, etc.) }\end{array}$ & $44 \%$ & $36 \%$ & $35 \%$ & $25 \%$ \\
\hline $\begin{array}{c}\text { Responsibility related to job } \\
\text { description }\end{array}$ & $11 \%$ & $3 \%$ & $18 \%$ & - \\
\hline Relationships with colleagues & - & $3 \%$ & $3 \%$ & - \\
\hline Relationship with superiors & - & - & $3 \%$ & - \\
\hline Lack of time for the rest & $22 \%$ & $13 \%$ & $23 \%$ & - \\
\hline Amount of work & $22 \%$ & $41 \%$ & $45 \%$ & $100 \%$ \\
\hline Deadlines & $22 \%$ & $21 \%$ & $28 \%$ & - \\
\hline Complexity of work & - & $13 \%$ & $25 \%$ & - \\
\hline Provision with resources & - & $5 \%$ & $13 \%$ & - \\
\hline Passive activity & $11 \%$ & $5 \%$ & $10 \%$ & - \\
\hline Monotonous/ boring tasks & $33 \%$ & $18 \%$ & $8 \%$ & - \\
\hline Circadian rhythms effect & $11 \%$ & $8 \%$ & $13 \%$ & - \\
\hline Work schedule & - & $8 \%$ & $28 \%$ & - \\
\hline
\end{tabular}

\section{Research results}

The research results of maintenance staff fatigue, obtained during a survey of employees of one of the organizations, allow us to draw the following main conclusions:

1. According to the majority of respondents, errors are the most likely outcome of work in a state of fatigue.

2. The majority of the respondents indicate that the deterioration of attention is one of the main reasons for errors made during aircraft maintenance.

3. Working hours of more than 50 hours per week begin to have a significant effect on maintenance staff fatigue towards worsening.

4. The majority of respondents experience tolerable alertness even with a total sleep duration of less than 18 hours for 3 days, while only a small part notices severe fatigue and attention problems. These data confirm the difficulty of a person's objective assessment of his real state of fatigue.

5. Only a third of the respondents take breaks in work every hour, while a significant number of respondents indicate a complete lack of time for breaks. The duration of the break is mostly from 5 to 15 minutes, in some cases the break duration is from 30 minutes to 1.5 hours.

6. The most common factors causing increased maintenance staff fatigue are sleep problems (sleep debt, insomnia, poor sleep quality, etc.), working conditions (noise, lighting, temperature, ergonomics of the workplace, etc.) and amount of work.

The obtained results indicate the need to manage maintenance staff fatigue in aircraft maintenance. Currently, a unified approach to the considered issue has not been established. Based on the presented data, a methodology was developed for managing maintenance staff fatigue in aircraft maintenance organizations. 


\section{Methodology for managing maintenance staff fatigue}

The proposed methodology is based on a questionnaire, where the respondents are asked to answer questions regarding their state of fatigue, and fatigue assessment criteria. It should be noted that the questions of maintenance staff fatigue during business trips are not included in the questionnaire.

The questions contained in the questionnaire are asked in relation to the period of being awake, the duration of sleep for one and three days, the time of the beginning and the end of sleep, sleep fragmentation, the average duration of working hours (including overtime work), the distance of the commuting between home and work, the possibility to have a nap on the way, the presence of breaks in work and their average duration. In addition, it is necessary to assess your condition according to the following criteria: the presence of activity, lack of drowsiness, the prevalence of alertness over drowsiness, a tendency to deterioration in attention, good reaction, the prevalence of drowsiness over alertness, severe fatigue, difficulty in focusing attention, tolerable alertness, fatigue. Also, the questionnaire is aimed at identifying the factors that most often contribute to the maintenance staff fatigue, such as: working conditions (lighting, temperature, noise, ergonomics of the workplace, etc.), sleep problems (such as insomnia, sleep debt, poor sleep quality), increased responsibility associated with the performance of aircraft maintenance, the atmosphere in the work team, lack of breaks, workload, deadlines, work complexity, provision with resources, passive activity, monotony of aircraft maintenance tasks, circadian rhythms effect and work schedule.

Fatigue evaluation according to the established criteria (Tables 5 and 6) allows making management decisions regarding the admissibility of aircraft maintenance.

Compliance with the values for each criterion in the table 5 should lead to a complete prohibition of the assessed employee to perform aircraft maintenance.

Table 5. Fatigue assessment criteria set №1

\begin{tabular}{|l|c|}
\hline \multicolumn{1}{|c|}{ Criterion } & Value \\
\hline How long have you been awake at this moment? & $>20 \mathrm{~h}$ \\
\hline What is the total duration of your sleep per day? & $<2 \mathrm{~h}$ \\
\hline
\end{tabular}

Compliance with the values for each criterion in the table 6 should lead to a limitation of the privileges of the assessed employee concerning to critical tasks, or to additional quality control of the work performed by such person.

Limitation of the employee's privileges in relation to critical tasks is required provided that:

- there is compliance with the values for four or more criteria in table 6;

- there is a compliance with the values for three criteria of the table 6 together with affirmative answers regarding the assessment of their condition: the prevalence of drowsiness over alertness or fatigue;

- there is a compliance with the values for two or more criteria of the table 6 together with affirmative answers regarding the assessment of their condition: a tendency to deterioration in attention or severe fatigue, difficulty in focusing attention.

Quality control of the work performed during aircraft maintenance is required provided that:

- there is a compliance with the values for two or three criteria of the table 6;

- there is a compliance with the values for one criterion of the table 6 together with affirmative answers regarding the assessment of their condition: the prevalence of drowsiness over alertness or fatigue. 
Table 6. Fatigue assessment criteria set №2

\begin{tabular}{|c|c|}
\hline Criterion & Value \\
\hline How long is your commuting to / from work? & $>2 \mathrm{~h}$ \\
\hline Was your sleep interrupted? & Yes, $>15 \mathrm{~m}$ \\
\hline What is the total duration of your sleep three days before the current \\
moment? & $>18 \mathrm{~h}$ \\
\hline What is your average working time per week (including overtime work)? & $>47 \mathrm{~h}$ \\
\hline $\begin{array}{c}\text { Is it possible for you to take a break every hour during the work performance } \\
\text { with the current workload? }\end{array}$ & $\begin{array}{c}\text { Without breaks, or } \\
\text { h for } 10 \mathrm{~m} \text { or less }\end{array}$ \\
\hline
\end{tabular}

The survey allows to find out other factors that contribute to the maintenance staff fatigue, for example, working conditions, workload, deadlines, work complexity, etc.

These factors require separate consideration and development of appropriate measures to reduce the fatigue of maintenance staff.

The obtained results, which have been tested in the activities of one of the maintenance organizations, indicate the need for a complete prohibition on the performance of tasks for $10 \%$ of employees. The limitation of privileges concerning to critical tasks is necessary for $5 \%$ of employees. $36 \%$ of employees require additional quality control of the work they perform.

\section{Conclusions}

The importance of maintenance staff fatigue in aircraft maintenance is often underestimated. Currently, aviation legislation, both Russian and foreign, does not pay sufficient attention to the issues of its management. At the same time, it is obvious that maintenance staff fatigue is a key factor contributing to the occurrence of errors in aircraft maintenance. Moreover, a high workload of maintenance staff, night work, performing maintenance tasks in shifts, increased physical and mental stress, constant time constraints allotted for maintenance, aggravate the severity of the effects of fatigue, significantly reducing the flight safety level. Undoubtedly, the maintenance staff fatigue issue is urgent.

The methodology presented in this article for managing fatigue in aircraft maintenance organizations implements the accumulated experience of maintenance staff, information about which is collected from questionnaires filled in by aviation specialists. Based on the results of the survey, criteria for assessing maintenance staff fatigue were developed, which make it possible to implement the necessary corrective and preventive measures, including limiting privileges, a complete prohibition on performing maintenance tasks, and additional quality control of the performed work.

Clarification of assessment criteria and, in general, improvement of the proposed methodology based on the results of its wider testing may be the next logical step towards solving the problem of maintenance staff fatigue.

\section{References}

1. Vorobev V.V., Enikeev R.V., Kozlovsky A.P., Nikolaykin N.I., Prozorov S.E., Rybalkina A.L., Ryabinin V.A., Susalev E.A., Chuntul A.V. and Sharov V.D. The human factor: lecture texts, Ed. Dr. tech. sciences, prof. Vorobev V.V. , Moscow (2018) 
2. Kozlov V.V. Flight Safety: from provision to management, JSC "Aeroflot-Russian Airlines", Moscow (2010)

3. N. Korolija, Lundberg J., Speaking of human factors: emergent meanings in interviews with professional accident investigators, Safety Science, v. 48(2), pp. 157-165 (2010)

4. Man and flight safety: scientific and practical aspects of aviation accident reduction due to the human factor, Ed. V.A. Ponomarenko, A.V. Chuntul, Moscow, (2013)

5. M. O'leary, The British Airways human factors reporting programme, Reliability Engineering \& System Safety, v. 75(2), pp. 245-255 (2002)

6. Safety Behaviours: Human Factors Resource Guide for Engineers, Civil Aviation Safety Authority (CASA) of Australia (2013)

7. A.L. Rybalkina, A.S. Semenov, Fatigue risk management in aircraft maintenance as an aspect of the human factor, XXI Century: Resumes of the Past and Challenges of the Present plus, v. 8(1), pp. 159-63 (2019)

8. Lapin V.L., Popov V.M., Ryzhkov F.N., Tomakov V.I. Safe human interaction with technical systems: textbook,State technical university Kursk, Kursk, (1995)

9. Bodrov V.A., Orlov V.Ya. Psychology and reliability: a person in technology control systems , Publishing House «Institute of Psychology RAS», Moscow (1998)

10. Jackson Craig A., Earl Laurie, Prevalence of fatigue among commercial pilots, Occupational Medicine, v. 56(4), pp. 263-268 (2006)

11. Doc 9966. Fatigue Risk Management Systems - Manual for Regulators, First edition, ICAO (2012)

12. L.L. Di Stasi, M.B. Mccamy, S. Martinez-Conde, S.L. Macknik, A. Catena, E. Gayles, C. Hoare, M. Foster, Effects of long and short simulated flights on the saccadic eye movement velocity of aviators, Physiology \& Behavior, v. 153, pp. 91-96 (2016)

13. Monmollen M. Systems «man and machine», Mir Publishing House, Moscow (1973)

14. A. Shanmugam, T.P. Robert, Human factors engineering in aircraft maintenance: $A$ review, Journal of Quality in Maintenance Engineering, v. 21(4), pp. 478-505 (2015)

15. Ovcharov V.E. «The human factor» in aviation accidents (teaching materials), Polygraph, Moscow (2005) 